\title{
NA PISTA DE PRÁTICAS E PROFESSORES INOVADORES NA EDUCAÇÃO FÍSICA ESCOLAR
}

Mauro Sérgio da Silva * Valter Bracht **

\section{RESUMO}

A tradição (ou a Educação Física tradicional) vem demonstrando mais resistência à mudança do que o esperado pelo movimento renovador da década de 1980. Aos poucos as esperanças iniciais de mudanças massivas da prática, deram lugar a uma expectativa mais modesta de fomentar inovações ou mudanças locais. Uma mudança no enfrentamento teóricometodológico do problema está relacionada ao reconhecimento da importância do professor e de sua formação nesse processo, bem como, da consideração do ambiente concreto da escola, ou seja, o "chão da escola" ou o cotidiano escolar. Assim sendo, o presente artigo constitui-se numa tentativa de identificar e compreender os processos de inovação pedagógica na Educação Física, levados a efeito por professores em contextos específicos. Tem a intenção também, de dar visibilidade a estas experiências na expectativa de potencializar outras.

Palavras chave: Educação Física. Inovação. Prática pedagógica.

\section{INTRODUÇÃO}

Na nossa história recente o ensino da educação física esteve voltado, em grande parte, para o ensino das destrezas esportivas com vistas a introduzir os alunos nas práticas do esporte, sendo que o modelo para essa prática era, normalmente, o esporte de alto rendimento. Esta perspectiva foi adotada a partir do incentivo das políticas públicas para o setor (poder público, principalmente, o governo federal), que baseavam-se na idéia de que sua missão principal seria a de trabalhar para que as equipes esportivas, representantes da nação, obtivessem êxito nas competi-ções internacionais - a conhecida ideia da pirâmide esportiva. Dessa forma, nas décadas de 1960, 70 e 80 e grande parte da de 1990, cristalizou-se nas escolas brasileiras uma determinada prática pedagógica em Educação Física, configurando-se uma certa tradição, razão pela qual a denominamos aqui de Educação Física tradicional.

A partir da década de 80 , desenvolveu-se no Brasil um movimento de renovação da Educação Física. Uma das vertentes desenvolvida neste âmbito, propôs, para superar essa tradição, um ensino nas escolas que possibilitasse aos educandos uma apropriação crítica do acervo da cultura corporal de 
movimento. Além dessa perspectiva (Coletivo de Autores, 1992), várias outras propostas pedagógicas foram desenvolvidas e colocadas à disposição para 0 debate da comunidade da educação física brasileira (Hildebrandt e Laging, 1986; Kunz, 1994). Embora estudos demonstrem as grandes dificuldades para que essas propostas cheguem efetivamente à escola e lá sejam incorporadas ao cotidiano escolar, elas vêm sendo utilizadas por professores de Educação Física em diversas escolas, de diferentes estados e municípios de nosso país. São tentativas de interpretar e realizar, situada e contextualizadamente, aquelas propostas pedagógicas. No entanto, estas experiências estão dispersas e na maioria das vezes não sistematizadas, de maneira que seu potencial de disseminação e de estímulo para novas experiências não pode se realizar mais efetivamente. Entendemos, na esteira de Linhares (2002), que a potência criadora dessas experiências, depende também de nossa capacidade de reconhecê-las, de refletir suas promessas, possibilidades e limites, de interligá-las, sem achatá-las ou homogeneizá-las.

A Educação Física brasileira tem tido muita dificuldade de traduzir seus avanços epistemológicos e teóricos para o campo da intervenção pedagógica, em particular no âmbito escolar. O enfrentamento deste desafio tem colocado questões importantes para os processos de formação (inicial e continuada). Sabemos, por outro lado, dos limites destes processos quando verificamos 0 cotidiano dos espaços/tempos escolares e as diferentes posturas assumidas pelos professores. Nesse sentido, reconhece-se que o desempenho profissional vincula-se também (ou fundamentalmente) ao contexto específico de suas práticas pedagógicas. O que se percebe é que no interior dos espaços educacionais também emergem práticas pedagógicas inovadoras, as quais parecem não obedecer lógicas lineares, motivadas por razões que muitas vezes nos escapam.

Nossa intenção é então, compreender melhor os processos que levam professores a construir práticas inovadoras, no sentido de romper ou não dar continuidade à cultura escolar da Educação Física presente e hegemônica.

Colocar a questão nestes termos, ou seja, buscar práticas inovadoras, requer uma discussão sobre aquilo que pode ser chamado de "práticas inovadoras", ou seja, é preciso problematizar e discutir como utilizar esse conceito. Para iniciar essa discussão, elaboramos inicialmente uma 
caracterização (na forma de tipos ideais) das práticas pedagógicas em Educação Física, hoje presentes em nossas escolas.

Parece-nos ser possível, de forma reducionista, caracterizar três tipos de prática pedagógica em Educação Física em voga em nossas escolas, sendo as duas primeiras as mais comuns: primeiro, aquela que continua a tradição que se instalou nas escolas e que foi construída nas décadas de 70 e 80 (já aventada no início), uma segunda é aquela que caracterizamos como "desinvestimento" ("professor rola bola", "pedagogia da sombra") e, por fim, a menos comum, é aquela que busca inovar, busca modificar (nem sempre numa direção progressista) e, assim, desvia de alguma forma da tradição instalada.

Os professores do primeiro grupo costumam organizar o ensino a partir da ideia de que seu papel é ensinar aos alunos a prática de alguns esportes, particularmente, o volibol, o basquetebol, o handebol e o futsal ou futebol. Este ensino é normalmente organizado sistematicamente em unidades bimestrais, e segue o princípio do mais simples ao mais complexo, ou seja, as técnicas mais simples são ensinadas primeiramente para, depois, serem integradas ao jogo propriamente dito.

Os professores cuja prática pode ser caracterizada como "professor rola bola" e/ou como "pedagogia da sombra", geralmente não apresentam pretensão maior do que ocupar seus alunos com alguma atividade (desinvestimento pedagógico), com frequência se convertem em administradores de material didático. Por vezes, assumem uma postura de recreacionista ou compensadora do tédio produzido nas outras disciplinas (como matemática ou português). Esse fenômeno tem sido freqüentemente entendido como um problema individual, apenas do sujeito, contudo avolumamse os estudos que entendem ser imprescindível tentar compreender o mesmo também, como um produto da cultura escolar.

Em contraposição a estas duas caracterizações, poderíamos, em caráter preliminar, identificar características que perfazem um terceiro tipo de prática, que denominamos inovadora, aqui o/a professor/a busca: a) inovar os conteúdos da Educação Física, ampliando-os para além dos tradicionais esportes, tematizando outras manifestações da cultura corporal de movimento, além de considerar como conteúdos de aula os aspectos ligados ao conhecimento sobre a cultura corporal de movimento, como conhecimentos 
fisiológicos, antropológicos, sociológicos, etc. tratando-os contextualizadamente, portanto, articulando teoria e prática; b) modificar o trato deste conteúdo, não mais se resumindo a apresentar os gestos considerados corretos, e sim, envolvendo o aluno como sujeito do conhecimento, construindo um ambiente de co-gestão das aulas; c) utilizar diferentes formas de avaliação que envolvam o aluno nas decisões do que avaliar, como avaliar e, mesmo, no próprio ato de avaliação (auto-avaliação); d) articular a EF de forma mais clara e orgânica ao projeto pedagógico da escola. Essas características podem se apresentar isoladamente ou então de forma combinada.

Intencionalmente não classificamos e identificamos as vinculações teórico-metodológicas das três perspectivas descritas, uma vez que entendemos que os professores nas suas ações promovem um amálgama idiossincrático de diferentes perspectivas ou então, interpretações situadas das diferentes propostas presentes no campo da Educação Física brasileira.

Em relação à inovação pedagógica, as leituras demonstraram a multiplicidade de entendimentos desse conceito presente na literatura (SANCHO GIL, 1999; MESSINA, 2001; ABRAMOVAY et al., 2004). Além dessa multiplicidade e/ou variabilidade é preciso destacar (contribuindo para essa) a dimensão histórica e política desse conceito. No caso específico da Educação Física (e talvez no da Educação de maneira geral), nas décadas de 1980 e 90 tendeu-se a conferir à intenção de mudança da prática pedagógica um caráter mais imediatamente político, inclusive adjetivando a prática pedagógica como transformadora ou mesmo, revolucionária da ordem social. Ou seja, o critério central para julgar a inovação era sua contribuição para a transformação (ou não) da sociedade capitalista. É claro que esta é apenas uma conotação possível do conceito de inovação pedagógica. Outra poderia ser a vinculada à utilização de novas técnicas de ensino que lhe confeririam maior eficácia em termos de aprendizagem dos conteúdos, sem, no entanto, discutir o significado desses conteúdos para a vida do cidadão. Assim, percebemos logo que não é possível "definir tecnicamente" o conceito. Por outro lado, pareceu-nos também um equívoco metodológico, pré-estabelecer, rigidamente, o que seria considerada, na pesquisa, uma prática inovadora na forma de um tipo ideal. Estabelecemos então, apenas como ponto de partida uma caracterização bastante ampla e a ser utilizada com extrema flexibilidade, dando assim 
oportunidade para que o que fosse encontrado no campo empírico pudesse nos falar e se fazer ouvir, sem ser barrado e/ou eliminado a-priori por um conceito excessivamente rígido. Ou seja, o entendimento é o de que nosso (pré)-conceito (de inovação) deve se abrir ao diálogo com o mundo empírico para que se construa, nesse diálogo, uma compreensão do que pode significar práticas inovadoras. Com isso não estamos advogando estabelecer a tirania do fático ou a primazia do empírico, não estamos, portanto, abrindo mão de confrontar o fático com o contra-fático, em suma, com uma determinada concepção de Educação e Educação Física. Estamos procurando apenas evitar operar com uma concepção rígida e idealizada que se sobreponha, que submeta o mundo da vida (o empírico) à uma sua forma. Em princípio, poderíamos dizer que estamos interessados em inovações que alteram o sentido da prática e não apenas, acrescentem, por exemplo, conteúdos novos (por exemplo, além dos esportes convencionais como vôlei, basquete, etc. ensinar também os esportes radicais).

Nesse ensejo, cabe ressaltar que definir critérios não representa arranjar amarras, pois, como nos alerta Messina (2001, p. 232)

[...] mais do que nos interessarmos pela identificação de critérios para reconhecer inovações, poderíamos criar espaços que promovessem a possibilidade do pensar e do fazer reflexivos, em que as inovações teriam a oportunidade de apresentar-se, contradizer e transformar. Igualmente, o interesse central da rede de inovações se situaria, de acordo com esse esquema, antes na 'invenção' e recuperação de inovações do que na sua difusão.

Por isso não nos permitimos o equívoco de cristalizar um conceito, tendo em vista que não basta estudarmos o ensino com a intenção de melhor compreendê-lo, sem entender melhor como fazem aqueles que ensinam com certo sucesso (GAUTHIER, 1998). Assim, nosso objeto passa a ser não mais apenas a busca das razões ou das explicações (determinantes) das práticas inovadoras, mas elas próprias, no sentido de caracterizá-las contextualmente (e não apenas como tipos ideais). Compreender o seu processo de construção, publicizá-las e criticá-las, identificando suas potencialidades e limitações, fazem parte do escopo da pesquisa. 


\section{METODOLOGIA DA PESQUISA}

No âmbito do LESEF (Laboratório de Estudos em Educação Física do CEFD/UFES) estão em andamento uma série de estudos de caso focados na questão da "inovação pedagógica" bem como, no problema do que denominamos de "desinvestimento pedagógico". O que apresentamos neste texto baseia-se no trabalho de campo realizado em duas escolas da rede municipal de Vitória-ES com ênfase na idéia de inovação, sendo que um dos casos corresponde ao trabalho realizado por um dos autores do presente texto, o que confere à presente pesquisa um delineamento muito particular. No presente texto, enfatizamos a questão dos modos de fazer dos professores considerados inovadores, em detrimento da discussão dos processos que permitam compreender como e porque práticas inovadoras são gestadas.

$\mathrm{Na}$ pesquisa optamos pelo estudo de caso pelo viés da etnografia. A etnografia, assim como outras formas de investigação social implica numa intervenção social, portanto possui conseqüências políticas, e por isso demanda responsabilidade e compromisso com os valores e efeitos do trabalho desenvolvido no campo (HAMMERSLEY; ATKINSON, 1994). No trabalho de campo isso foi sendo delineado a partir de uma relação de confiança estabelecida entre pesquisador e colaborador. Confiança desenvolvida muito em virtude de os dois sujeitos adotarem postura colaboracionista para a construção de suas práticas e estarem dispostos a problematizar os trabalhos que desenvolviam nas escolas em que atuam. A possibilidade de trocar experiências foi um viés interessante para a construção das relações na pesquisa, notadamente, no que diz respeito ao pesquisador fazer parte da paisagem da escola, no intuito de obter dados de qualidade. Como uma investigação social a etnografia possui um caráter reflexivo, constitui um processo flexível, contudo, necessita de um delineamento, mesmo que este mude no decorrer da investigação. Assim sendo, inicialmente nos apropriamos de conceitos como o de cultura de Forquin (1993) e Guattari e Rolnik (1993) e cultura escolar de Vago (2003) e Forquin (1993), dentre outros. 


\section{Indícios de práticas e professores "inovadores"}

A escola da professora 1 possui quadra coberta, que faz divisa com a janela de três salas de aula, situação que força a criação de estratégias para o desenvolvimento da aula de forma que não atrapalhe a dinâmica das aulas nas salas. Ela tem por hábito falar com muita serenidade e de forma pausada. Jamais sai da sala de aula sem explicar aos alunos qual a proposta da aula e quais atividades serão realizadas, mesmo assim, não consegue abrir mão dos pedidos de silêncio em diversos momentos. O que sinaliza para um problema que é de ordem mais estrutural e estratégico, pois por ocasião da construção da escola não se pensou na funcionalidade dos espaços e isso não é um problema que os professores podem resolver, isso depende de construção de políticas que valorizem a escuta dos diversos sujeitos que interagem nesse espaço.

A escola do professor 2 não possui quadra esportiva, o espaço utilizado para aula é uma quadra que pertence à comunidade. Para chegar a ela, é necessário o deslocamento por duas ruas movimentadas e ao chegar à quadra seu uso é dividido, em diversas situações, com usuários de drogas, até que alunos ou pessoas da comunidade que estejam vigiando a quadra (pessoas geralmente ligadas ao tráfico, das quais os usuários de drogas têm medo) façam a "gentileza" de pedir que eles se retirem. Tendo essas condições estruturais para a aula, surge o problema de como equacionar o tempo da aula (problema que também afeta a professora 1), que é composto por vários tempos: tempos de explicação, de esclarecimento de dúvidas, de transporte até a quadra, de vivenciar as propostas da aula, de refletir e resolver os conflitos, de refletir e não resolver os conflitos, de retornar à escola. Esse equacionamento do tempo não é padronizado, mas faz parte da rotina e da vida da aula dessa escola.

Os dois professores chegaram às escolas em 2007 na condição de docentes com cadeira definitiva nestas instituições, portanto, compõem o quadro de professores permanentes de suas escolas. Ambos encontraram os planos de ação das escolas elaborados, com a programação oficial das atividades que seriam realizadas no ano de 2007, já definida. Nesse sentido, a contribuição para esse planejamento anual coletivo já estava comprometida. Tal fato foi importante para quem chegava à escola, pois demandou habilidade 
para saber administrar como e quando entrar nos espaços para que os posicionamentos políticos não gerassem estranhamentos. Por outro lado, também pensar em maneiras de dialogar e se colocar diante dos desafios/objetivos traçados por outrem, demonstrou ser uma postura essencial para a inserção na organização da cultura da escola. Os professores apresentaram como conduta comum, a realização de uma avaliação diagnóstica para identificar que rumos poderiam tomar, nesse ensejo algumas perguntas chaves foram utilizadas para identificar o tipo de relação que os alunos vinham estabelecendo com a educação física e o que conheciam de e como educação física, para encaminhar a disciplina e perspectivar que contribuições para os projetos da escola poderiam ser pensadas. No diagnóstico foram feitas as seguintes perguntas aos estudantes: o que fazemos nas aulas de educação física? Como fazemos nas aulas de educação física? Onde fazemos as aulas de educação física? Para que fazemos as aulas de educação física? A relação com o esporte e as aulas livres apareceram de forma pujante em ambos os casos, inclusive a confusão entre aula de educação física e treinamento esportivo.

O trabalho compromissado dos professores se apresentou como fomento a novos olhares e possibilidades de configuração da cultura da escola e, além de assegurar certa legitimidade com os alunos, tal compromisso se manifestou por meio: da dedicação ao planejamento; das decisões e construção das aulas compartilhadas com seus alunos; da tentativa de articulação das produções das aulas com os projetos previstos pela escola; da opção por práticas mais inclusivas; da ausência de preocupação exacerbada com os limites que a organização dos tempos escolares impõe, pois centram seus esforços no compromisso com a aprendizagem dos alunos (a escola da professora 1 organiza o ano por trimestres e a escola do professor 2 por bimestre). Quanto aos problemas que surgem nas aulas os professores têm como característica, estar atentos às maneiras de identificar a causa dos mesmos, para daí, pensar a intervenção possível, tendo no diálogo franco e aberto a estratégia principal.

No caso da professora 1, a atmosfera era mais favorável à colaboração. A professora percebeu as possibilidades de parcerias dentro da escola, como 
pudemos constatar num depoimento que fez durante um encontro de formação continuada sobre uma experiência com uma prática de esportes de aventura denominada "Enduro a Pé", no qual relata o comportamento de euforia na participação dos demais professores da escola e como as parcerias foram sendo edificadas de forma que o trabalho se tornou uma produção e compromisso da escola.

Os professores têm uma série de receios, frutos do isolamento em seus trabalhos nas escolas, mas enxergam nas trocas com os pares, possibilidades de construir elementos que assegurem um trabalho coerente com a realidade escolar e com seus interesses. A ausência de espaços para trocas entre pares inviabiliza o amadurecimento de boas ideias. Noutro sentido, foi possível observar que a relação do pesquisador com o meio, de forma que perspective contribuições para o espaço, pode fomentar ambientes favoráveis a propostas inovadoras nas aulas de educação física e para a escola, como foi o caso do desenvolvimento do enduro a pé pela professora 1. Recentemente, quando a professora 1 apresentou a experiência na formação continuada para o grupo de professores da rede, destacou a relevância de possuir parceiros da área para o diálogo constante, dadas as possibilidades de ampliação da reflexão e contraste de ideias. Os professores precisam assumir riscos, mas com a prudência necessária para não expor a escola a uma série de tentativas que não passem de delírios e que não contribuam para uma formação dos alunos com vistas a uma sociedade mais crítica, criativa, plural, democrática e solidária.

$\mathrm{Na}$ relação com a produção da área no que tange as concepções metodológicas para o ensino da educação física na escola, os professores apresentam em suas aulas aproximações com propostas consideradas progressistas. Pode ser observado nas aulas que, além dos conteúdos relacionados às destrezas motoras para a prática de alguma atividade, há uma preocupação grande no estabelecimento de relações com o contexto de inserção dos alunos, assim como despertar para outras possibilidades de construção de práticas corporais nos seus momentos de lazer. Reside nos discursos e práticas desses professores a necessidade de ampliar o olhar dos alunos sobre os temas tratados nas aulas. Como isso se manifesta? Por meio de uma preocupação em apresentar novas possibilidades de práticas e em 
construir conceitos sobre o tema trabalhado. Essa é considerada uma prática fundamental para que os estudantes tenham a oportunidade de ampliar seu acervo cultural e poder iniciar processos de reconstrução das práticas corporais atribuindo sentido próprio e ao mesmo tempo coletivo às práticas que porventura venham a utilizar nos seus momentos fora da escola e mesmo dentro dela. Tal postura está atrelada ao processo de formação dos professores que se orientam por perspectivas teóricas vinculadas à idéia da transformação social.

Os professores acreditam e incorporam significados pessoais à forma de organização da aula, que constitui um motivador para movimentos realizados por eles dentro dos espaços de intervenção e os levam a concretização de seus trabalhos. Outro ponto importante para sua atuação docente está diretamente ligado à maneira como o professor se relaciona com seu trabalho, isso num sentido de ver-se dentro de uma profissão, nesse caso, a de professor, que pode gerar em momentos diferentes, níveis de compromisso diferenciados.

Partindo do que observamos, inicialmente, os professores que inovam não ficam apenas aguardando para saber o que a escola irá proporcionar a eles, apesar disso consistir em um condicionante relevante. Entretanto, a avaliação da situação concreta da escola e do seu entorno, no que ele pode oferecer como condições de possibilidade, assume papel mais central na forma como o professor vai se relacionar com o que será tratado nas aulas. Isso pode estar vinculado à preocupação com o reconhecimento da importância da educação física como parte relevante do conhecimento escolar, além de seu reconhecimento como um profissional que está realizando seu trabalho da melhor forma possível.

Durante a imersão no cotidiano das escolas foram sendo identificadas relações que influenciam nas posturas e práticas dos professores, assim, emerge a íntima relação entre a produção das práticas (inovadoras) escolares e a cultura da escola, pois, as condições postas pela cultura existente na escola influenciam de forma contundente a maneira como as pessoas que estão envolvidas no processo de aprendizagem-ensino vão se comportar ao longo do ano letivo. Em nossa pesquisa a cultura da escola como um condicionante, interferiu nas produções das culturas escolares da educação 
física. No caso 1 estudado, por exemplo, a professora consegue estabelecer um trabalho com características de colaboração, estabelecendo várias parcerias dentro da escola em diversas instâncias, e no caso 2 estudado, 0 trabalho apresenta um caráter mais de isolamento.

\section{CONSIDERAÇÕES FINAIS E PERSPECTIVAS DO ESTUDO}

A produção das inovações tem íntima relação com as histórias de vida dos professores e a forma como se relacionam com sua profissão. Fator potencializador das inovações são as mudanças ocorridas nos referenciais orientadores para a construção da prática, fato que altera também o sentido das intervenções. Os professores que tentam construir práticas num sentido inovador, parecem estar muito preocupados com a relevância daquilo que vai ser tratado nas aulas para a vida dos estudantes e o reconhecimento do trabalho que desenvolvem.

Fica claro também, através das relações dos professores estudados com seus estudantes, que a relação de poder deve ser estabelecida com o saber que será disponibilizado no processo de aprendizagem-ensino e, não, em relação ao estudante, pois seria contraproducente para uma prática que se pretende mais democrática, a prevalência apenas das vontades do professor, desse modo, as questões que surgem em função da relação professor-aluno devem primar por dimensões como a do afeto, da aprendizagem e não da obrigatoriedade sem significação para o estudante. Para tanto, urge pensar numa perspectiva diferenciada de formação de professores que vislumbre outros níveis de relação entre histórias de vida, conhecimento acadêmico, produção de saber, sentimentos em relação ao trabalho e à profissão. Nessa linha, o professor assumiria posturas mais autônomas para o desenvolvimento do trabalho em suas salas de aulas. Cabe salientar que os registros escritos que os professores fazem, se problematizados, podem suscitar alternativas para a reconstrução de uma paisagem escolar mais criativa e coerente com as realidades nas quais os professores estão inseridos. A pesquisa da própria prática é um caminho possível, porém, com muitas limitações, principalmente por ser um processo pouco claro para a maioria dos professores, inclusive para a academia que ainda precisa pensar melhor essa modalidade de formação. 
Para a compreensão das práticas dos professores que buscam construir práticas inovadoras, faz-se necessário o esclarecimento de alguns pontos para o avanço na formação inicial e continuada dos professores, tais como: como vem ocorrendo o processo de formação de professores que intentam a reformulação das formas de aprendizagem? Nos casos aqui descritos vem ocorrendo por meio de pequenos grupos de diálogo crítico e na socialização das experiências vividas com um núcleo mais central oferecido pelo órgão gestor, bem como as pesquisas que são feitas para fundamentação das práticas trabalhadas nas aulas de educação física. Onde buscam sustentação para suas ideias? Os dois professores orientam seus trabalhos em perspectivas progressistas do ensino da educação física, como Kunz (1998 e 2000), Coletivo de Autores (1992), isso demonstra que as propostas metodológicas críticas chegam à escola, mas não são reproduzidas por esses professores, são apropriações, pelo menos nesses dois casos, que eles fazem por entenderem que estas são coerentes com suas formas de ver e viver 0 mundo. Quais são seus referenciais de partida? As experiências que tiveram anteriormente como praticantes de algumas modalidades, a escuta das necessidades dos estudantes, as pesquisas pela internet e diálogo com pares. Em que se ancoram os docentes para resolver os problemas? Uma ferramenta básica para resolver os conflitos da aula tem sido o diálogo franco e problematizador das situações que ocorrem em aula, e, a partir deste diálogo são deliberados os encaminhamentos para as aulas, mas existe uma linha tênue entre a desordem total e a abertura para opiniões/sugestões; nesse diálogo, o professor deve estar atento para interromper o processo se necessário e propor/direcionar para outro caminho caso veja necessidade. Difícil é estabelecer o ponto de inflexão a partir do qual a autoridade vira autoritarismo, situação que de fato pode ocorrer dependendo do "calor da hora". Em que medida um repertório de saberes, reconhecidos como válidos, pode auxiliar na reflexão e avanço das práticas? As sucintas respostas colocadas aqui apontam que é possível a construção de experiências inovadoras em Educação Física, mas que, sobretudo, é imprescindível que tais experiências ganhem maior repercussão para que possam ser problematizadas e ampliadas. Queremos ressaltar que essas questões precisam ser mais bem 
debatidas e compreendidas para que sejam potencializados os processos de formação de professores.

Não há receitas para a construção de inovações numa perspectiva transformadora da Educação Física da escola. Há caminhos: o que a professora 1 utilizou, partindo da experiência de outro colega, pode sinalizar para uma possibilidade de construção coletiva de trabalhos para a Educação Física coerentes com o espaço de intervenção, e, na mesma medida, potencializador de novos horizontes para a ampliação do acervo dos estudantes em relação aos temas da cultura corporal de movimento. $O$ percurso da inovação pode levar a vários destinos, o que vai determinar sua orientação são os fundamentos e a análise crítica do que se pretende com a educação que a escola proporciona. A reflexão crítica da prática assume papel importante para evitar que a construção de "coisas novas" tenha um fim em si mesmo. Nesse sentido, faz-se mister ressaltar que para a realização de processos de mudança significativos e persistentes na educação, devemos reconhecer o papel central dos professores no desenvolvimento dos processos educacionais, bem como a valorização e reconhecimento da profissão docente. Processos de formação verdadeiramente continuados e salários dignos, podem auxiliar na construção de motivações para o desenvolvimento dos trabalhos. Quanto à organização desta formação, pudemos vislumbrar na formação de pequenos grupos de diálogo críticos, nos quais se oportunize o estudo e reflexão das experiências de professores inovadores, uma estratégia profícua. Nessa pesquisa, por exemplo, o espaço de troca entre os professores foi produtivo para a construção de uma proposta de trabalho que envolveu toda uma escola. Contudo, estes círculos não podem ser fechados, pois a articulação e a discussão das produções dos pequenos grupos com comunidades ampliadas de diálogo é fundamental para evitar uma endogenia, que, em muitos casos, é limitadora da criatividade e inibidora da auto-crítica.

\section{REFERÊNCIAS}

ABRAMOVAY, M. et. al. Escolas inovadoras: experiências bem-sucedidas em escolas públicas. Brasília: UNESCO, Ministério da Educação, 2004. 
COLETIVO DE AUTORES. Metodologia do ensino da educação física. São Paulo: Cortez, 1992.

FORQUIN, J. C. Escola e cultura: as bases sociais e epistemológicas do conhecimento escolar. Porto Alegre: Artes Médicas, 1993.

GATTARI, F.; ROLNIK, S. Micropolítica: cartografias do desejo. Petrópolis: Vozes, 1993.

GAUTHIER, C. et al. Por uma teoria da pedagogia: pesquisas contemporâneas sobre saber docente. ljuí: Unijuí, 1998.

HAMMERSLEY, M.; ATKINSON, P. Etnografía: métodos de investigación. 2 ed. Barcelona: Paidós, 1994.

HILDEBRANDT, R. e LAGING, R. Concepções abertas no ensino da educação física. Rio de Janeiro: Ao Livro Técnico, 1986.

MESSINA, Graciela. Mudança e inovação educacional: notas para reflexão. Cadernos de Pesquisa, São Paulo, n.114, 2001. Disponível em: http://www.scielo.br/scielo.php?script=sci arttext\&pid=S0100$15742001000300010 \&$ Ing=pt\&nrm=iso . Acesso em: 28 jun 2007.

KUNZ, E. (Org.) Didática da educação física 1. ljuí: Ed. Unijuí, 1998.

KUNZ, E. Transformação didático-pedagógica do esporte. 3 ed. ljuí: Ed. Unijuí, 2000.

LINHARES, C. Experiências instituintes em escolas públicas II. Universidade Federal Fluminense, 2002 (projeto de pesquisa, mimeog.).

SANCHO GIL, J. M. Inovação e investigação educativa: aproximação a uma relação incerta. In. MOLINA NETO, V.; TRIVIÑOS, A. N. S. (Org.) A pesquisa qualitativa na Educação Física: alternativas metodológicas. Porto Alegre: UFRGS/Sulina, 1999, p. 29-45. 
VAGO, T. M. A Educação Física na cultura escolar: discutindo para a intervenção e a pesquisa. In. BRACHT, V. CRISÓRIO, R. (coords.). A Educação Física no Brasil e na Argentina: identidade, desafios e perspectivas. Campinas, SP: Autores Associados; Rio de Janeiro: PROSUL, 2003, p.197-221.

\section{IN THE ROUTE OF INNOVATIVE PRACTICES AND TEACHERS IN THE SCHOOL PHYSICAL EDUCATION}

\section{ABSTRACT}

The tradition (or the traditional Physical Education) has been more resistant to changes than the expected by the 1980's renewal movement. Gradually, the initial expectations of massive changes in the practices gave rise to a more modest expectation of encouraging local innovations or changes. A change in the theoretical and methodological facing of the problem can be linked to the recognition of the importance of teachers and their training in that process, and to the consideration of the school reality, that is, the school routine. In this sense, this article constitutes an attempt to identify and understand the processes of pedagogical innovation in the Physical Education area, carried out by teachers in specific contexts. This text also aims at giving visibility to these experiences in the hope of potentializing others.

Key-words: Physical Education. Innovation. Pedagogical Practice.

\section{EN LA RUTA DE PRÁCTICAS Y PROFESORES INNOVADORES EN LA EDUCACION FÍSICA ESCOLAR}

\section{RESUMEN}

La tradición (o la Educación Física tradicional) viene demostrando más resistencia al cambio que lo esperado por el movimiento renovador de la década de 1980. Poco a poco, las esperanzas iniciales de cambios masivos de la práctica dieron lugar a una expectativa más modesta de fomentar innovaciones o cambios situados más localmente. Un cambio en el enfrentamiento teórico-metodológico del problema está relacionado al reconocimiento de la importancia del maestro y de su formación en ese proceso, así como de la consideración del ambiente concreto de la escuela, es decir, en el cotidiano escolar. De ahí, el presente artículo se constituí en un intento de identificar y comprender los procesos de innovación pedagógica en la Educación Física, llevados a cabo por maestros en contextos específicos. Busca, también, dar visibilidad a estas experiencias con la expectativa de potenciar otras.

Palabras clave: Educación Física. Innovación. práctica pedagógica. 